Tropical Journal of Pharmaceutical Research May 2017; 16 (5): 1021-1028

ISSN: $1596-5996$ (print); 1596-9827 (electronic)

(C) Pharmacotherapy Group, Faculty of Pharmacy, University of Benin, Benin City, 300001 Nigeria.

All rights reserved.

Available online at http://www.tjpr.org

Original Research Article

http://dx.doi.org/10.4314/tjpr.v16i5.8

\title{
Green tea polyphenol induces significant cell death in human lung cancer cells
}

\author{
Jie Huang, Fa-jiu Li, Shi Chen, Yi Shi, Xiao-jiang Wang, Chuan-hai Wang, Qing- \\ hua Meng, Cheng Jiang, Zhi-yang Zhu and Cheng-Hong Li* \\ Department of Respiratory Medicine, Wuhan No.6 Hospital, Affiliated Hospital of Jianghan University, Wuhan, People's
} Republic of China

*For correspondence: Email: lichenghong323@hotmail.com; Tel/Fax: 0086-027-82426502

Sent for review: 26 June $2016 \quad$ Revised accepted: 14 April 2017

\begin{abstract}
Purpose: To investigate the dose-response relationship of green tea polyphenol in an animal model of lung cancer.

Methods: The effects of epigallocatechin-3-gallate (EGCG) on the inhibition of xenograft tumor growth, the accumulation of 8-hydroxy-2'-deoxyguanosine (8-OHdG), and apoptosis based on 3-(4,5dimethylthiazol-2-yl)-2,5-diphenyltetrazolium bromide (MTT) assay were evaluated in non-small cell lung cancer (NSCLC) cell lines, namely, H1155, H661, and A427 (a human lung carcinoma-derived cell line). The dose-dependent effects of EGCG on H1155 xenograft tumor growth, as well as the levels of EGCG in plasma and tissue, were also determined in male nude mice.

Results: EGCG inhibited the growth of NSCLC-derived cell lines (H1155) over a 45-day period. There was a significant reduction (57 \%) in tumor weight in EGCG-fed $(0.5 \%)$ animals compared with the control group $(p<0.05)$. Linear regression analysis revealed a dose-dependent reduction in tumor size. MTT assay results revealed inhibition of $\mathrm{H1155}$ cell growth $(25 \%, p<0.05)$ after $24 \mathrm{~h}$ treatment with EGCG. The addition of superoxide dismutase $(5 \mathrm{U} / \mathrm{mL})$ and catalase $(30 \mathrm{U} / \mathrm{mL})$ reduced the inhibitory effect of EGCG. Mice administered $30 \mathrm{mg} / \mathrm{kg}$ EGCG via intraperitoneal injection exhibited the least amount of oxidative stress.

Conclusion: The results demonstrate the concentration-dependent inhibitory effects of EGCG on lung cancer cells, including H1155 cells, both in vitro and in vivo. The induction of reactive oxygen species, oxidative DNA damage, and apoptosis were evident following EGCG treatment.
\end{abstract}

Keywords: Green tea, Lung cancer, Catechins, Epigallocatechin-3-gallate, Oxidative stress, Oxidative DNA damage

Tropical Journal of Pharmaceutical Research is indexed by Science Citation Index (SciSearch), Scopus, International Pharmaceutical Abstract, Chemical Abstracts, Embase, Index Copernicus, EBSCO, African Index Medicus, JournalSeek, Journal Citation Reports/Science Edition, Directory of Open Access Journals (DOAJ), African Journal Online, Bioline International, Open-J-Gate and Pharmacy Abstracts

\section{INTRODUCTION}

Following water, tea is the most widely consumed drink throughout the world. Leaves of the Camellia sinensis plant (either cured or green) are used to make the beverage. The leaves of $C$. sinensis are rich in polyphenols commonly referred to as catechins, which are composed of (-)-epigallocatechin-3-gallate
(EGCG), (-)-epicatechin-3-gallate, (-)-epigallocatechin, and (-)-epicatechin.

EGCG is the most abundant polyphenol in tea. The anti-cancer properties of green tea polyphenols have already been described elsewhere. However, its dose-response relationship has not been established in an animal model $[1,2]$. A low dose of EGCG $(0.04$ $\%)$ inhibits tumors in experimental models $[3,4]$. 
However, few studies have demonstrated the efficacy of green tea polyphenols at much higher concentrations (e.g., $0.3 \%$ \%) [5,6]. Tumor inhibition was also observed following intraperitoneal (i.p.) injection of EGCG $[7,8]$. A concentration of $4-150 \mu \mathrm{M}$ EGCG is used in most in vitro experiments; however, the bioavailability of EGCG is less than $0.5 \mu \mathrm{M}$ [9]. Several studies have noted a lack of understanding the correlation between the doseresponse and anti-tumor activity in vivo; an obvious gap in the relationship between dose and metabolism has also attracted much criticism $[1,10]$.

Reactive oxygen species (ROS) are the most common causative factor of cell stress and DNA damage [11]. Evaluation of the DNA oxidative product 8-hydroxy-2'-deoxyguanosine (8-OHdG) is useful for studying ROS-mediated oxidative stress [12-14]. Rad3-related kinase and mutated ataxia-telangiectasia can also be used as markers of DNA damage $[15,16]$. The present study aimed to identify the dose-response relationship of EGCG in human lung cancer $\mathrm{H} 1155$ cells and its role in oxidative stress.

\section{EXPERIMENTAL}

\section{Cell culture}

Non-small cell lung cancer (NSCLC) cell lines $\mathrm{H} 1155$, H661, and A427 (a human lung carcinoma-derived cell line), the human colorectal adenocarcinoma cell line SW1417, and mouse-derived lung adenocarcinoma LA-4 cells were obtained from the American Type Culture Collection (ATCC; Manassas, VA, USA). $\mathrm{H} 1155, \mathrm{H} 661$, and LA-4 cells were maintained in Roswell Park Memorial Institute (RPMI)-1640 medium; A427 cells were maintained in F-12K medium supplemented with $10 \%$ fetal bovine serum (FBS). SW1417 cells were maintained in L15 medium supplemented with $2 \mathrm{mM}$ glutamine and $10 \%$ FBS. Cells were cultured under standard culture conditions of $37^{\circ} \mathrm{C}$ and $5 \%$ $\mathrm{CO}_{2}$. Milli-Q® water was used to dissolve EGCG, and a concentration range of $5-50 \mu \mathrm{M}$ EGCG was used. 3-(4,5-dimethylthiazol-2-yl)-2,5diphenyltetrazolium bromide (MTT), superoxide dismutase (SOD), and catalase assays were performed using commercially available kits from Cayman Chemicals (Ann Arbor, Michigan, USA) according to the manufacturer's protocols.

\section{In vivo experiments}

All animal procedures were performed according to the guidelines of the Care and Use of Laboratory Animals and were approved by the
Animal Ethical Care and Use Committee of Anhui Medical University, China (Ethical Permit 04/S0356/728). All experimental procedures were conducted in compliance with institutional guidelines and conformed to the National Research Council Guide for the Care and Use of Laboratory Animals [17]. Male nude mice were purchased from Sino-British Lab Animal Ltd. (Shanghai, China) and were fed an AIN93M diet (Keaoxieli Diet Co., Beijing, China). Mice were divided into four groups with 12 mice per group. Six-week-old mice were injected with $\mathrm{H} 1155$ cells $\left(1 \times 10^{6}\right.$ cells) subcutaneously (s.c.) in both flanks. Each group received different concentrations of EGCG. Two groups received oral administration of EGCG (0.1 and $0.5 \%$ ), while one group received $30 \mathrm{mg} / \mathrm{kg}$ EGCG administered via intraperitoneal (i.p.) injection; the fourth group served as a control group (no EGCG administered). Each animal was monitored for tumor size and body weight. After $45 \mathrm{~d}$ of treatment, all mice were sacrificed via euthanasia by $\mathrm{CO}_{2}$ asphyxiation. The tumor tissue was resected and used for biological analysis.

\section{Plasma and tissue levels of EGCG}

Tissue samples were analyzed according to a procedure described by Lee et al [16]. Briefly, 0.1 $\mathrm{g}$ of tissue was homogenized in $0.05 \mathrm{~mL}$ of $1 \%$ ethyl acetate and $0.45 \mathrm{mM}$ ascorbic acid in methanol. After centrifugation, $500 \mu \mathrm{L}$ of the supernatant was extracted twice with $1 \mathrm{~mL}$ hexane. After the second extraction, samples were mixed with $10 \mu \mathrm{L}$ of $0.2 \%$ ascorbic acid and dried. Dried samples were reconstituted in $100 \mu \mathrm{L}$ of $10 \%$ aqueous acetonitrile. Fifty microliters of sample were then injected into a high-performance liquid chromatography (HPLC) system. Results are expressed as $\mu \mathrm{mol} / \mathrm{kg}$ on the basis of wet weight.

\section{Immunohistochemistry}

Excised tumor tissues from nude mice were fixed in paraformaldehyde for $24 \mathrm{~h}$ and embedded in paraffin. Sections $(4 \mu \mathrm{m})$ of the paraffinembedded tissues were examined on polylysine-coated slides. Slides were rinsed twice in $300 \mathrm{~mL}$ phosphate-buffered saline (PBS) and blocked at room temperature for $1 \mathrm{~h}$. Slides were then incubated with the appropriate primary antibody (in antibody dilution buffer) and incubated in a humidified chamber at room temperature for $1 \mathrm{~h}$. After washing with PBS, slides were incubated with the appropriate secondary antibody. Sections were counterstained with hematoxylin and observed under a light microscope (Nikon, Shinagawa, 
Tokyo, Japan). Images were quantified using ImageJ software (National Institutes of Health, Bethesda, MD, USA).

\section{Analysis of apoptotic cells}

After treatment with EGCG, $\mathrm{H} 1155$ cells were harvested by trypsinization. For staining, $2-5 \times$ $10^{5}$ cells (per $\mathrm{mL}$ ) were resuspended in $500 \mu \mathrm{L}$ HEPES N-[2-hydroxyethyl] piperazine-N'-[2ethanesulphonic acid]-buffered saline ( $\mathrm{pH} 7.4)$. The cell suspension $(190 \mu \mathrm{L})$ was added to 10 $\mu \mathrm{L}$ annexin $\mathrm{V}$-fluorescein isothiocyanate (Invitrogen Molecular Probes, South San Francisco, CA, USA), mixed gently, and incubated at room temperature for $15 \mathrm{~min}$. Cells were centrifuged and propidium iodide buffer (1 $\mu \mathrm{g} / \mathrm{mL}$ ) was added. A 488-nm laser coupled to a cell sorter (Cytomics ${ }^{\circledR}$ FC500; Beckman Coulter Inc., Miami, FL, USA) was used for flow cytometric analysis.

\section{Statistical analysis}

Results are presented as the mean \pm standard deviation (SD). The Kruskal-Wallis test (one-way analysis of variance [ANOVA] on ranks) was used for statistical analysis. A $P$ value $<0.05$ was considered to indicate a statistically significant difference. Spearman's rank correlation was used to determine the degree of association between continuous variables. SPSS (version 11.5; SPSS Inc., Chicago, IL, USA) was used for data analysis.

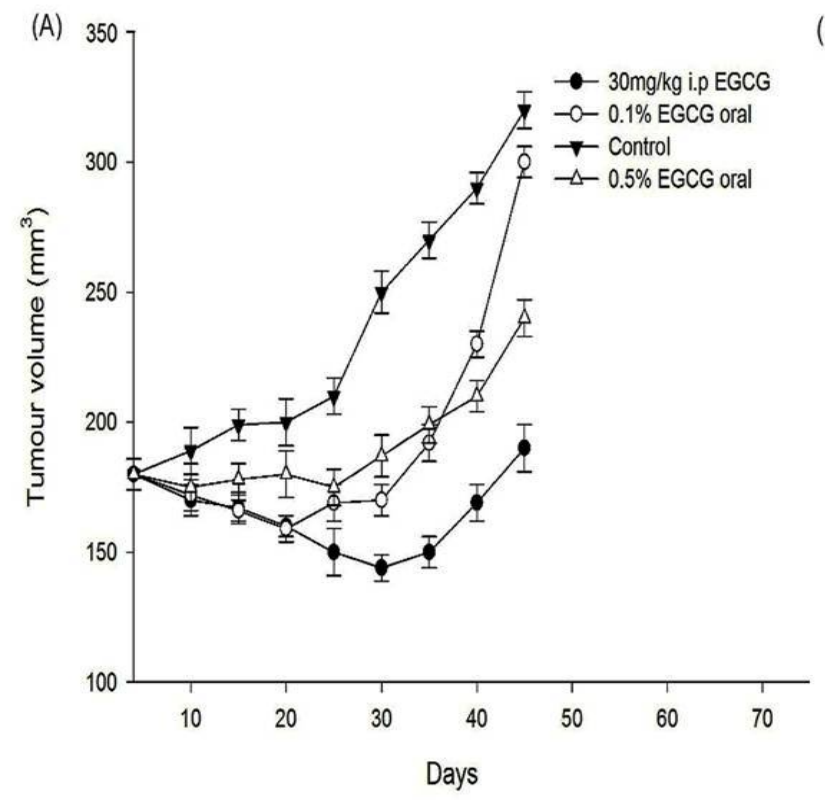

\section{RESULTS}

\section{Dose-response inhibition of H1155 xenograft tumor growth by EGCG}

There were no changes in body weight gain or food intake among any of the five animal cohorts. EGCG inhibited the growth of the NSCLCderived cell line (H1155) over 45 d (Figure 1). There was a significant reduction $(57 \%)$ in tumor weight in EGCG-fed animals (0.5\%) compared with the control group $(p<0.05)$. Linear regression analysis revealed that the reduction in tumor weight correlated in a dose-dependent fashion ( $y=0.945-1.027 x, R^{2}=0.97$; where $y$ $=$ tumor weight $(\mathrm{g})$ and $x$ is the \% EGCG content administered orally). In addition, the i.p. administration of EGCG $(30 \mathrm{mg} / \mathrm{kg})$ resulted in significant inhibition (69\%).

\section{EGCG concentration in biological samples}

A dose-dependent increase in EGCG concentration was observed in the blood and xenograft tumors after oral administration of EGCG (0.1 or $0.5 \%)$. The increase in EGCG was much higher via the i.p. route $(30 \mathrm{mg} / \mathrm{kg}$ EGCG). The mean plasma EGCG levels were $0.02,0.25,0.51$, and $3 \mu \mathrm{mol} / \mathrm{L}$ in control, 0.1 and $0.5 \%$ EGCG (oral), and $30 \mathrm{mg} / \mathrm{kg}$ EGCG (i.p.) animals, respectively (Figure 2A). The mean EGCG concentrations in xenograft tumors were $0.045,0.15,0.19$, and $0.4 \mu \mathrm{mol} / \mathrm{kg}$ in control, 0.1 and $0.5 \%$ EGCG (oral), and $30 \mathrm{mg} / \mathrm{kg}$ EGCG (i.p.) animals, respectively (Figure 2B).

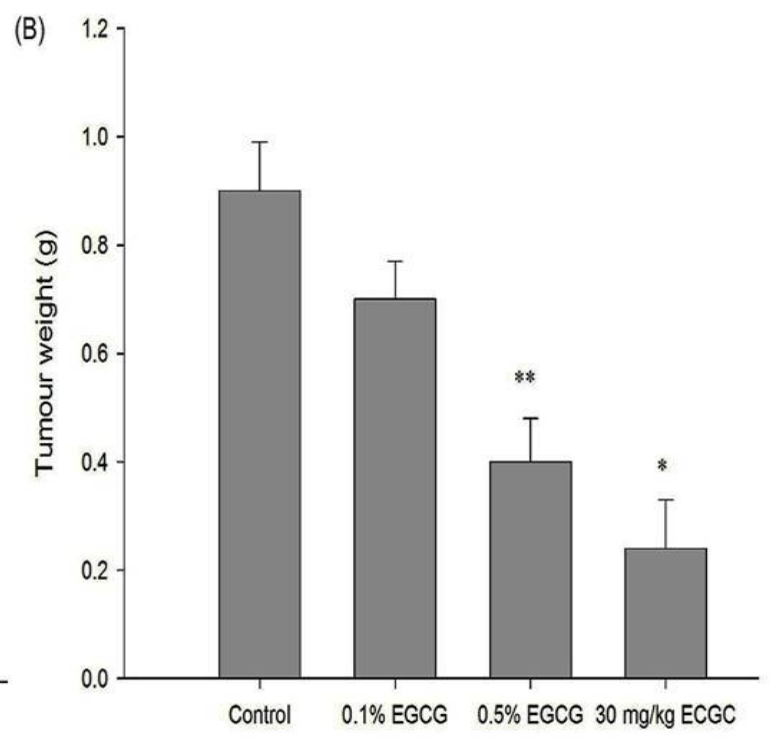

Figure 1: Inhibition of $\mathrm{H} 1155$ lung cancer xenografts after treatment with EGCG. (A) Time versus mean tumor volume. (B) Effect of EGCG on tumor weight. Values are presented as the mean \pm standard error (SE). A P value less than 0.05 was considered significant 

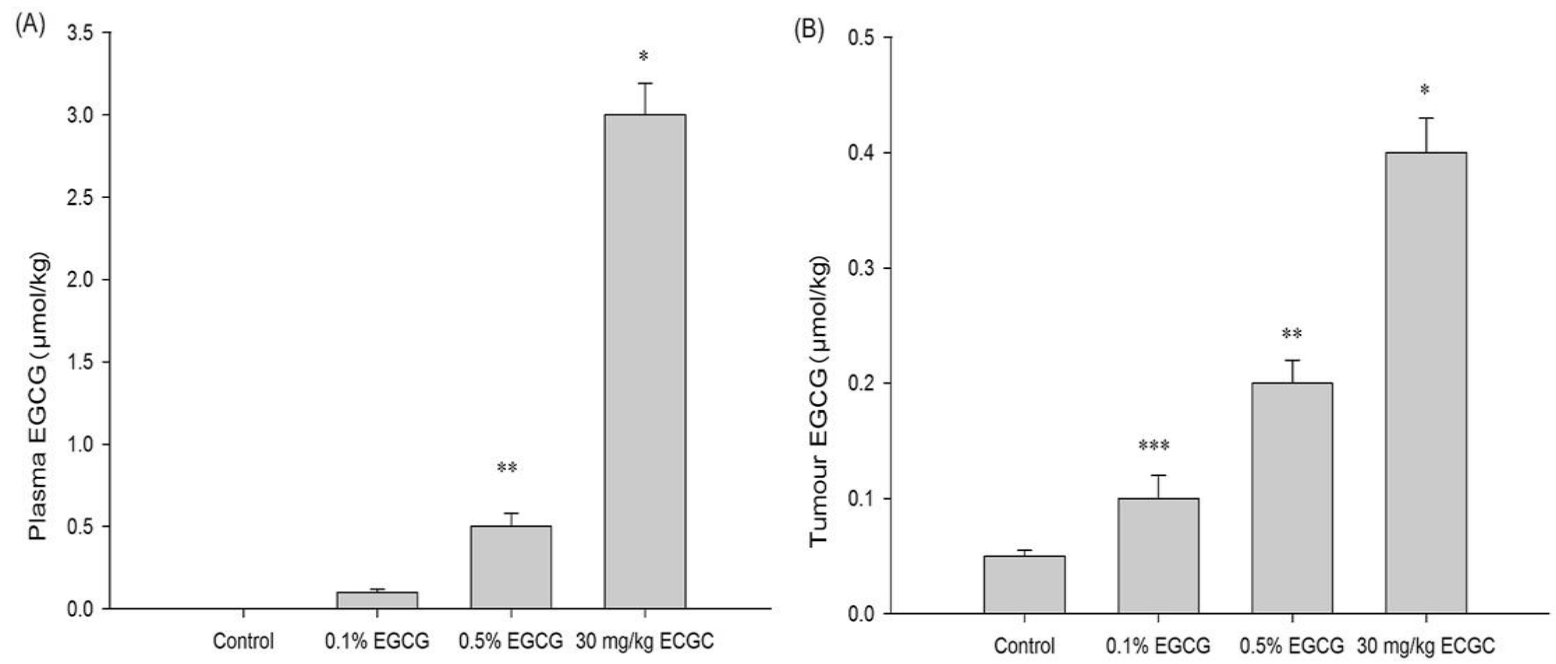

Figure 2: (A) EGCG levels in plasma and (B) tumors. Values are presented as mean $\pm \mathrm{SE}$; * indicates a significant value

It was previously reported that EGCG appears at 0.5 of $3-4 \mathrm{~h}$ and takes $90-120 \mathrm{~min}$ to reach peak plasma levels $(4,12)$. In our study, the plasma levels achieved may represent only half of the peak plasma levels since blood was collected in the morning and feeding mostly occurred at night. The $\mathrm{IC}_{50}$ value calculated by the regression analysis was $0.15 \mu \mathrm{mol} / \mathrm{kg}$. The plasma EGCG level was 5-fold higher in animals administered EGCG via i.p. injection than the oral route.

\section{Evaluation of oxidative stress parameters in xenograft tumors}

DNA damage due to oxidative stress was investigated by immunohistochemical analysis of the accumulation of $8-\mathrm{OHdG}$. Positive-control tissue was treated with $\mathrm{H}_{2} \mathrm{O}_{2}$. The treatment group consisted of animals administered 0.1 and 0.5 \% EGCG orally and $30 \mathrm{mg} / \mathrm{kg}$ EGCG via i.p. injection. As expected, a greater accumulation of 8-OHdG was observed in the positive control. An increase in 8-OHdG expression was also observed in EGCG-treated animals. Animals administered $30 \mathrm{mg} / \mathrm{kg}$ EGCG via i.p. injection showed the least amount of oxidative stress (Figure 3A).

\section{Cancer inhibitory effect of EGCG}

The inhibitory effect of EGCG was evaluated by the MTT assay, which showed that EGCG inhibited $\mathrm{H} 1155$ cells after treatment for $24 \mathrm{~h}$. The number of apoptotic cells increased in a concentration-dependent manner (Figure 4). The presence of SOD $(5 \mathrm{U} / \mathrm{mL})$ and catalase (30 $\mathrm{U} / \mathrm{mL}$ ) reduced the inhibitory action of EGCG.
Similar results were obtained when the same experiment was repeated in different cell lines. A437 and SW1417 cells showed the weakest response to EGCG treatment. These results support the hypothesis that the inhibitory effect of EGCG may be due to the generation of ROS.

\section{DISCUSSION}

The present study demonstrates that EGCG exhibits significant concentrationdependent inhibitory effects against the growth of lung cancer $\mathrm{H} 1155$ cells in tumor xenografts as well as in culture. Furthermore, EGCG markedly increased the levels of ROS in a concentrationand time-dependent manner both in vitro and in vivo. Moreover, our current findings reveal that EGCG activates the generation of ROS, leading to oxidative DNA damage in $\mathrm{H} 1155$ cells and in a tumor xenograft model.

Previous studies have suggested several mechanisms of action for the inhibitory effects of EGCG on cancer cell growth and development. However, various experiments have proposed only two anti-cancer mechanisms of EGCG. The first involves the interaction between EGCG and specific proteins wherein EGCG binds to target proteins and consequently modulates gene expression and signaling pathways associated with carcinogenesis, either directly or indirectly.

Many EGCG target proteins have been identified, including vimentin [17], HIF-1a, FYN (FYN ProtoOncogene, Src Family Tyrosine Kinase) [18], laminin receptor [19], and insulin-like growth factor 1 receptor $[4,20]$, 

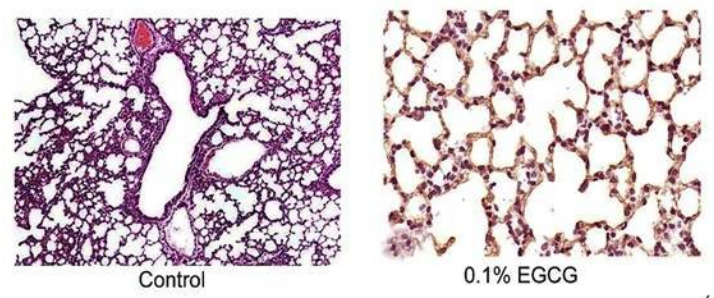

$0.1 \%$ EGCG

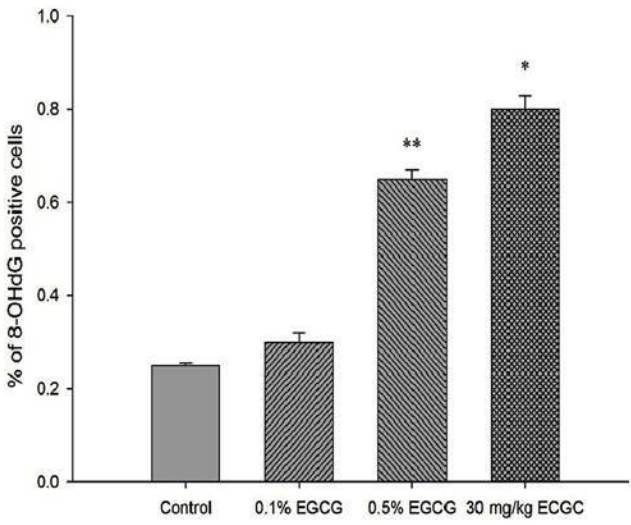

(B)

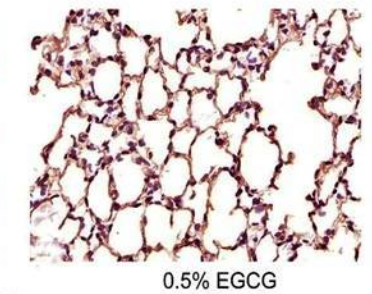

(A)

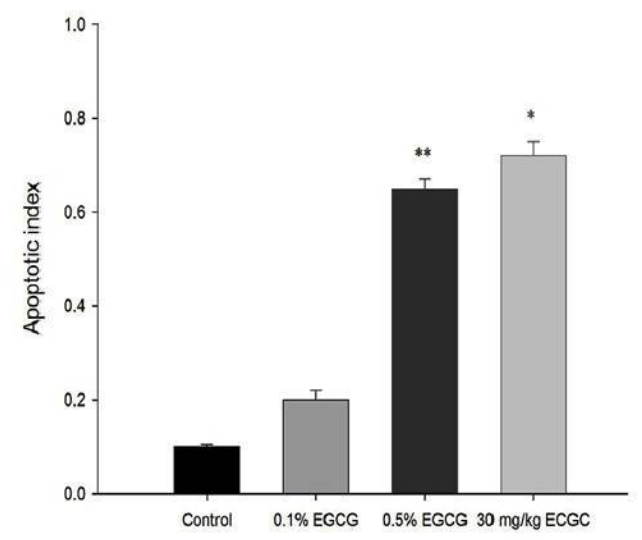

(C)

Figure 3: (A) Photomicrographs representing the effects of EGCG and 8-hydroxy-2'-deoxyguanosine (8-OHdG) accumulation in xenograft tissues. (B) Percentage of 8 -OHdG-positive cells. (C) Apoptotic index in different treatment groups. Values are presented as mean \pm SE
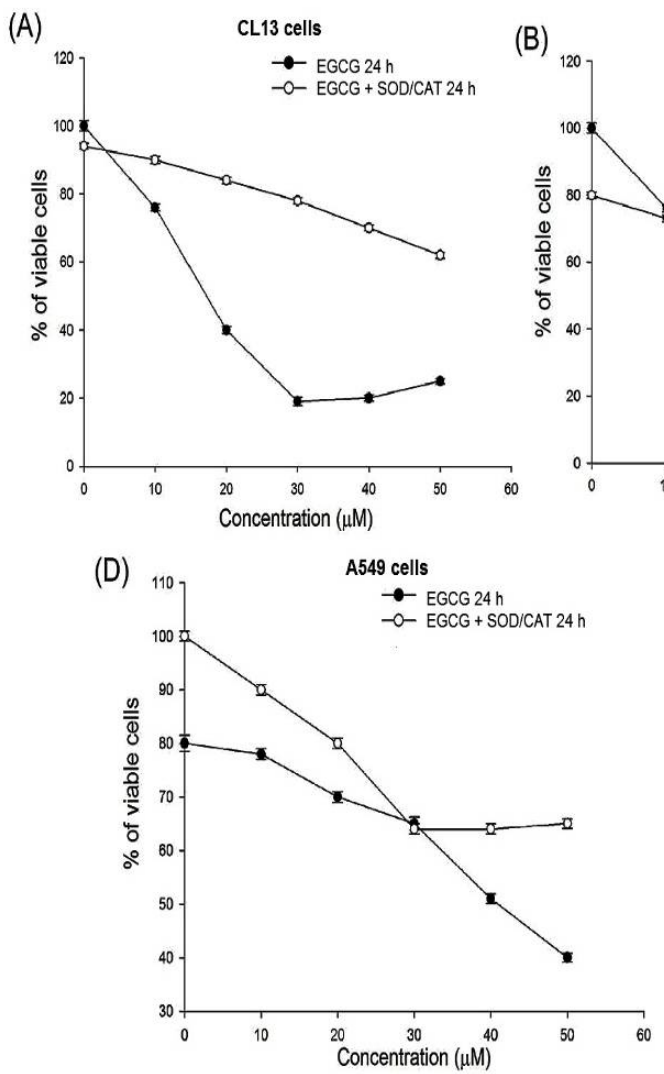

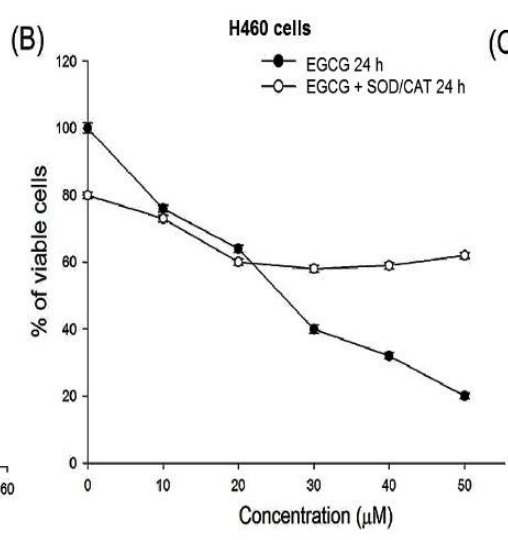

(E)

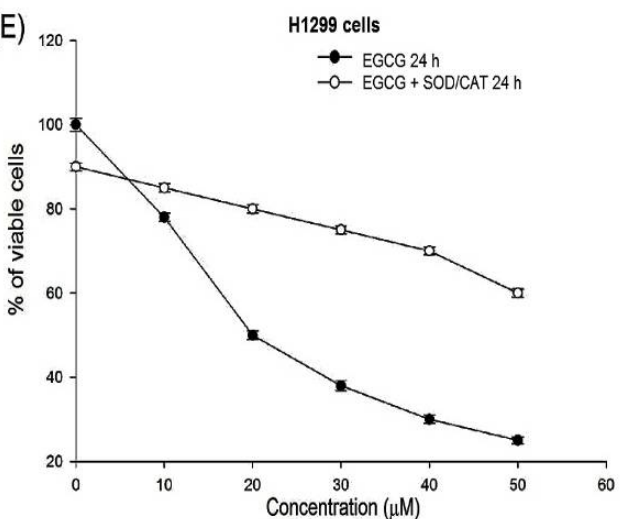

Figure 4: Inhibitory effect of EGCG in different cell lines. (A) Percentage of viable CL13 cells. (B) Percentage of viable H460 cells. (C) Percentage of viable HT29 cells. (D) Percentage of viable A549 cells. (E) Percentage of

$\mathrm{H} 1299$ cells.

Values

are

presented

as

mean

\pm standard

deviation

(SD) 
that exhibit increased binding affinity towards EGCG. The second mechanism of action of EGCG includes the increased production of ROS, which leads to apoptosis and damage to cancer cells. We demonstrated this mechanism in the present study in the experimental cell line, wherein EGCG induced a concentrationdependent growth reduction of $\mathrm{H} 1155$ lung cancer cells. The growth of H1155 lung cancer cells was reduced in a concentration-dependent manner, with an estimated $I_{50}$ value of $20 \mu \mathrm{M}$. This inhibition of viable $\mathrm{H} 1155$ cells was observed due to ROS-activated apoptosis via EGCG. Additionally, most of the ROS produced were blocked by the addition of SOD and catalase. These results are similar to the report in which EGCG-induced apoptosis was inhibited by catalase in lung cancer H661 cells [20].

The present study aimed to investigate the concentration-dependent anti-carcinogenic effects of EGCG on H1155 lung cancer cells, including the involvement of oxidative stress in a tumor xenograft animal model and in culture. In this study, treatment with EGCG resulted in a concentration-dependent inhibition of the growth of H1155 lung cancer cells in tumor xenografts and in culture. The dose of EGCG correlated with the inhibition of cancer cell growth, as shown by linear regression analysis. Furthermore, an estimated $\mathrm{IC}_{50}$ value of $0.15 \mu \mathrm{M}$ in vivo is much lower than the $\mathrm{IC}_{50}$ value of $20 \mu \mathrm{M}$ in vitro (Figure 4 ), indicating that the effective concentration of EGCG was much higher in culture (in vitro) compared with the dose in the animal model (in vivo) [21].

Many studies support that EGCG exhibits greater inhibitory effects against cancer cell growth in vitro compared with in vivo. Nevertheless, both in vitro and in vivo systems differ and thus comparative results could be equivocal. Therefore, linear regression analysis was used to compare the results of in vitro and in vivo studies. A remarkable difference in the effective inhibitory concentration of EGCG was observed in the xenograft animal model, which may be due to long-term exposure to EGCG in the xenograft animal study versus short-term exposure to EGCG in vitro. Moreover, previous research demonstrated that a longer treatment duration can decrease the effective EGCG concentration in culture [22].

Environmental conditions used in cell culture are unlike those in a xenograft animal model. EGCG degradation likely results in ROS generation outside of cells in culture, leading to apoptosis, whereas ROS is mostly generated inside of cells in a xenograft model. Furthermore, our results demonstrated that intracellular ROS induced following EGCG treatment were attenuated by the addition of SOD and catalase in H1155 cells. SOD and catalase remarkably attenuated the ROS produced following treatment with EGCG $(50 \mu \mathrm{M})$ for $24 \mathrm{~h}$. However, considerable levels of ROS remained because of the presence of intracellular ROS inside of the cells. N-acetylcysteine (NAC), an antioxidant, decreased ROS production to control levels both extracellularly and intracellularly. These results demonstrate the similar effects of the EGCG-induced generation of mitochondrial ROS and changes in mitochondrial membrane potential.

We observed an association between oxidative stress and DNA damage in EGCG-induced apoptosis in the xenograft tumor, which was demonstrated by the concentration-dependent generation of 8-OHdG following EGCG treatment. The induction of oxidative stress in tumors by EGCG is possible due to the presence of the transcription factor NF-E2-related factor-2 and hemeoxygenase-1, which control the expression of various antioxidants and detoxification of enzymes [23,24]. However, the effects of NF-E2-related factor-2 and hemeoxygenase-1 are comparatively greater in SW1417 and A427 cells, which exhibited a weaker response to EGCG inhibition and SOD/catalase protection.

\section{CONCLUSION}

The findings of the present study demonstrate the concentration-dependent inhibitory effects of EGCG on lung cancer cells ( $\mathrm{H} 1155$ cells) both in vitro and in vivo. EGCG induces ROS, and its involvement in apoptosis, as well as oxidative DNA damage, has been established. This study supports the use of green tea as a supplementary food to prevent cancer progression.

\section{DECLARATIONS}

\section{Acknowledgement}

We acknowledge that our study was granted by Hubei Province health and family planning scientific research (project no. WJ2017M169).

\section{Conflict of Interest}

No conflict of interest associated with this work.

\section{Contribution of Authors}

The authors declare that this work was done by 
the authors named in this article and all liabilities pertaining to claims relating to the content of this article will be borne by them.

\section{Open Access}

This is an Open Access article that uses a funding model which does not charge readers or their institutions for access and distributed under the terms of the Creative Commons Attribution License (http://creativecommons.org/licenses/by/ 4.0) and the Budapest Open Access Initiative (http://www.budapestopenaccessinitiative.org/rea d), which permit unrestricted use, distribution, and reproduction in any medium, provided the original work is properly credited.

\section{REFERENCES}

1. Yang CS and Wang ZY. Tea and cancer. J Natl Cancer Inst 1993; 85: 1038-1049.

2. Lambert JD, Hong J, Yang GY, Liao J, Yang CS. Inhibition of carcinogenesis by polyphenols: evidence from laboratory investigations. Am J ClinNutr 2005; 81: 284S-291S

3. Naasani I, Oh-Hashi F, Oh-Hara T, Feng WY, Johnston $J$, Chan K, Tsuruo T. Blocking telomerase by dietary polyphenols is a major mechanism for limiting the growth of human cancer cells in vitro and in vivo. Cancer Res 2003; 63: 824-830.

4. Nishida $H$, Omori $M$, Fukutomi $Y$, Ninomiya M, Nishiwaki $S$, Suganuma M, Moriwaki H, Muto $Y$. Inhibitory effects of (-)-epigallocatechin gallate on spontaneous hepatoma in $\mathrm{C} 3 \mathrm{H} / \mathrm{HeNCrj}$ mice and human hepatoma-derived PLC/PRF/5 cells. Jpn J Cancer Res 1994; 85: 221-225.

5. Liao J, Yang GY, Park ES, Meng $X$, Sun $Y$, Jia $D$, Seril $D N$, Yang CS. Inhibition of lung carcinogenesis and effects on angiogenesis and apoptosis in $\mathrm{A} / \mathrm{J}$ mice by oral administration of green tea. Nutr Cancer 2004; 48: 44-53.

6. Wang $D$, Carretero $O A$, Yang $X Y$, Rhaleb NE, Liu YH, Liao TD, Yang XP. N-acetyl-seryl-aspartyl-lysyl-proline stimulates angiogenesis in vitro and in vivo. $A m \mathrm{~J}$ Physiol Heart CircPhysiol 2004; 287: H2099-H2105.

7. Xu Y, Ho CT, Amin SG, Han C, Chung FL. Inhibition of tobacco-specific nitrosamine-induced lung tumorigenesis in A/J mice by green tea and its major polyphenol as antioxidants. Cancer Res 1992; 52: 3875 3879.

8. Liao S, Umekita Y, Guo J, Kokontis JM, Hiipakka RA. Growth inhibition and regression of human prostate and breast tumors in athymic mice by tea epigallocatechin gallate. Cancer Lett 1995; 96: 239-243.

9. Yang CS, Sang S, Lambert JD, Lee MJ. Bioavailability issues in studying the health effects of plant polyphenolic compounds. Mol Nutr Food Res 2008; 52 Suppl 1: S139-S151.
10. Hong J, Lu H, Meng X, Ryu JH, Hara Y, Yang CS. Stability, cellular uptake, biotransformation, and efflux of tea polyphenol (-)-epigallocatechin-3-gallate in HT-29 human colon adenocarcinoma cells. Cancer Res 2002; 62: 7241-7246.

11. Barzilai $A$ Yamamoto K. DNA damage responses to oxidative stress. DNA Repair (Amst) 2004; 3: 11091115.

12. Albino $A P$, Huang $X$, Jorgensen $E$, Yang J, Gietl $D$, Traganos $F$, Darzynkiewicz Z. Induction of H2AX phosphorylation in pulmonary cells by tobacco smoke: a new assay for carcinogens. Cell Cycle 2004; 3: 10621068.

13. Burma $S$, Chen BP, Murphy $M$, Kurimasa A, Chen DJ. ATM phosphorylates histone H2AX in response to DNA double-strand breaks. J BiolChem 2001; 276: 4246242467.

14. Sarma $K$ Reinberg $D$. Histone variants meet their match. Nat Rev Mol Cell Biol 2005; 6: 139-149.

15. van AH Gasser SM. The histone code at DNA breaks: a guide to repair? Nat Rev Mol Cell Biol 2005; 6: 757-765.

16. Zhou N, Xiao H, Li TK, Nur-E-Kamal, Liu LF. DNA damage-mediated apoptosis induced by selenium compounds. J BiolChem 2003; 278: 29532-29537.

17. NRC [National Research Council]. 1996. Guide for the Care and Use of Laboratory Animals. 7th ed. Washington DC: National Academy Press.

18. Lee MJ, Prabhu S, Meng X, Li C, Yang CS. An improved method for the determination of green and black tea polyphenols in biomatrices by high-performance liquid chromatography with coulometric array detection. Anal Biochem 2000; 279: 164-169.

19. Tachibana H, Koga K, Fujimura $Y$, Yamada K. A receptor for green tea polyphenol EGCG. Nat StructMolBiol 2004; 11: 380-381.

20. Li M, He Z, Ermakova S, Zheng D, Tang F, Cho YY, Zhu F, Ma WY, Sham Y, Rogozin EA, Bode AM, Cao Y, Dong Z. Direct inhibition of insulin-like growth factor-I receptor kinase activity by (-)-epigallocatechin-3-gallate regulates cell transformation. Cancer Epidemiol Biomarkers Prev 2007; 16: 598-605.

21. Moiseeva EP Manson MM. Dietary chemopreventive phytochemicals: too little or too much? Cancer Prev Res (Phila) 2009; 2: 611-616

22. Shimizu M, Deguchi A, Lim JT, Moriwaki H, Kopelovich L, Weinstein IB. (-)-Epigallocatechin gallate and polyphenon $E$ inhibit growth and activation of the epidermal growth factor receptor and human epidermal growth factor receptor-2 signaling pathways in human colon cancer cells. Clin Cancer Res 2005; 11: 2735 2746.

23. Itoh $K$, Chiba $T$, Takahashi S, Ishii $T$, Igarashi $K$, Katoh $Y$, Oyake T, Hayashi N, Satoh K, Hatayama I, Yamamoto M, Nabeshima Y. An Nrf2/small Maf heterodimer mediates the induction of phase II detoxifying enzyme genes through antioxidant response elements. BiochemBiophys Res Commun 1997; 236: 313-322. 
Huang et al

24. Nguyen T, Yang CS, Pickett CB. The pathways and molecular mechanisms regulating Nrf2 activation in response to chemical stress. Free RadicBiol Med 2004; 37: 433-441. 